\title{
Prevalence and Risk Factors for Irritable Bowel Syndrome among Male Secondary School Saudi Students in Najran City, Saudi Arabia
}

\author{
ABDULAZIZ SAAD ALSHAHRANI, M.D. \\ The Department of Internal Medicine, College of Medicine, Najran University, Najran, Saudi Arabia
}

\begin{abstract}
Background: Patients with IBS have higher healthcare resource utilization than non-IBS patients in terms of more frequent physician visits, more tests, greater medication use, and increased rates of unnecessary surgery.

Aim of Study: This study aimed to assess prevalence, types, and risk factors of irritable bowel syndrome among Saudi Male Secondary School Students in Najran City, Saudi Arabia.

Patients and Methods: A cross-sectional study design was followed during February 2020. The study included 400 Male Secondary School Saudi students in Najran City, Saudi Arabia. Aself-administeredquestionnaire was used for data collection. It included personal characteristics, and the IBS questionnaire. A total of 159 male secondary school students (39.8\%) expressed symptoms suggestive of IBS. Alternating diarrhea and constipation (i.e., IBS-M) was the most common type $(26.3 \%)$, followed by those with diarrhea (i.e., IBS-D), (7.3\%), and those with constipation (i.e., IBS-C), (6.3\%). Some variables were associated with significantly higher prevalence of IBS among male secondary school students, i.e., positive family history of IBS, and diabetes mellitus.

Conclusions: Prevalence of IBS symptoms among malesecondary school students in Najran City is high. IBS-Mis the most common type, followed by IBS-D. Positive family history of IBS, and diabetes mellitus are associated with significantly higher prevalence of IBS among students. Therefore, it is recommended to provide health education for secondary school students on how to manage and alleviate symptoms of IBS.
\end{abstract}

Key Words: Irritable bowel syndrome - Adolescents - School students - Risk factors - Saudi Arabia.

\section{Introduction}

IRRITABLE bowel syndrome (IBS) is a highly prevalent common chronic functional gastrointestinal disorder. It has a great impact on health care and patients' quality of life. It is characterized by altered bowel habits with abdominal pain or dis-

Correspondence to: Dr. Abdulaziz Saad Alshahrani,

The Department of Internal Medicine, College of Medicine, Najran University, Najran, Saudi Arabia comfort, withthe absence of detectable organic pathology [1]

Globally, IBS is an important public health problem. Nevertheless, it still has an uncertain etiology, often associated with non-colonic symptoms. The disorderis one of the most common conditions encountered by physicians and accounts for approximately $12 \%$ of visits to primary health care physicians and $28 \%$ of the referrals to gastroenterologists [2]

IBS is often sub-classified, according to the predominant stool pattern experienced by the patient, into diarrhea-predominant (IBS-D), constipation-predominant (IBS-C), or mixed, alternating bowel habit (IBS-M). However, this doesnot always exhibithigh stability during extended follow-up [3].

The diagnosis of IBS is symptom-based. Accurate and timely diagnosis, together with the appropriate intervention, are critical for optimal management [4]. In the absence of warning symptoms, physicians can confidently diagnose IBS during the first or second patient visit without extensive testing or specialist advice. Surgical procedures can be avoided and treatment can be initiated as early as possible, and only a minority may need to be referred to the gastroenterologists. After diagnosis, IBS patients should be reassured and educated about their condition, and the appropriate diet therapy and symptomatic treatment to control constipation and/or diarrhea should be offered [4]

The prognosis of IBS is usually benign, but its symptoms may mimic those of more severe conditions, such as inflammatory bowel disease or colon cancer [5]. Despite the high prevalence of this condition, only about $30 \%$ of patients with IBS seek the advice of a physician for evaluation and treatment [6]. 
Irritable bowel syndrome is a troublesome condition. It is associated with a great economic burden owing to substantial direct health care costs and indirect costs. Patients with IBS have higher healthcare resource utilization than non-IBS patients in terms of more frequent physician visits, more tests, greater medication use, and increased rates of unnecessary surgery [7]

Many researchers in various countries studied IBS patients in hospitals or in primary healthcare settings. However, publications on prevalence of IBS among adolescents or secondary school students in Saudi Arabia are quite scarce. Therefore, it is important to assess IBS, and its types among secondary school students [8].

\section{Patients and Methods}

During February 2020, a cross-sectional study design was followed in Najran City, Saudi Arabia. Following a simple random sample, three governmental secondary schools for boys were selected. A total of 400 Saudi male secondary school students were randomly included in the present study.

A study questionnaire was designed by the researcher for data collection. It comprised personal characteristics of participants and the IBS questionnaire, which was constructed according to the Rome IV Criteria [9]. According to participants' responses, they were subclassified into diarrheapredominant IBS (IBS-D), constipation-predominant IBS (IBS-C), or mixed IBS (IBS-M).

All necessary administrative approvals were fulfilled before data collection. The ethical approval \#22-06-01-2020 EC was acquired from Najran University Institutional Research Board on January 5 th, 2020. Before filling the study questionnaire, written informed consent was obtained from each participant.

The Statistical Package for Social Sciences (IBM, SPSS version 25) was used for data entry and analysis. Descriptive statistics (e.g., frequencies and percentages) were calculated, and the $x^{2}$ testwas applied accordingly. A statistically significant difference was considered when the $p$-value was less than 0.05 .

\section{Results}

Table (1) shows that age of most students ranged from 21 to 24 years $(82.5 \%)$. The prevalence of smoking among students was $17.5 \%$, while the prevalence of diabetes was $3 \%$. Almost one-third of students $(32 \%)$ had a positive family history of irritable bowel syndrome.
Table (2) shows that 159 male students (39.8\%) had IBS. The IBS-M type was of highest prevalence among students, followed by IBS-D (26.3\% and $7.3 \%$, respectively).

Table (3) shows that among male secondary school students, the prevalence of irritable bowel syndrome was higher among older age groups and smokers. However, prevalence did not differ significantly according to their age groups or smoking status. Diabetic students had a significantly higher prevalence of IBS than non-diabetic ones $(83.3 \%$, $38.4 \%$, respectively, $p=0.002$ ). Hypertensive students had a higher prevalence of IBS than nonhypertensive ones $(40 \%, 39.7 \%$, respectively). However, prevalence did not differ significantly according to the presence of hypertension. Students with a positive family history of IBS had significantly higher prevalence of IBS than those with a negative family history $(56.3 \%, 32.0 \%$, respectively, $p<0.001)$.

Table (1): Personal characteristics of participant male secondary school students in Najran City, Saudi Arabia

\begin{tabular}{lll}
\hline Personal characteristics & No. & $\%$ \\
\hline Age groups (in years): & & \\
$\quad<15$ & 34 & 8.5 \\
$15-18$ & 330 & 82.5 \\
$>18$ & 36 & 9.0 \\
Cigarette smoking: & & \\
$\quad$ Smoker & 70 & 17.5 \\
Non-smoker & 330 & 82.5 \\
Diabetes mellitus: & & 3.0 \\
Yes & 12 & 97.0 \\
No & 388 & \\
Hypertension: & & 2.5 \\
Yes & 10 & 97.5 \\
No & 390 & \\
Family history of IBS: & & 32.0 \\
Yes & 128 & 68.0 \\
No & 272 & \\
& &
\end{tabular}

Table (2): Prevalence and types of irritable bowel syndrome amongmale secondary school students in Najran City, Saudi Arabia.

\begin{tabular}{lll}
\hline Characteristics & No. & $\%$ \\
\hline Irritable bowel syndrome: & & \\
$\quad$ Absent & 241 & 60.3 \\
Present & 159 & 39.8 \\
Types of irritable bowel syndrome: & & \\
IBS-C & 25 & 6.3 \\
IBS-D & 29 & 7.3 \\
IBS-M & 105 & 26.3 \\
\hline
\end{tabular}


Table (3): Risk factors for irritable bowel syndrome (IBS) among male secondary school students in Najran City, Saudi Arabiaaccording to their personal characteristics.

\begin{tabular}{|c|c|c|c|c|c|}
\hline \multirow{2}{*}{$\begin{array}{l}\text { Personal } \\
\text { characteristics }\end{array}$} & \multicolumn{2}{|c|}{$\begin{array}{c}\text { Absent } \\
(\mathrm{n}=241)\end{array}$} & \multicolumn{2}{|c|}{$\begin{array}{l}\text { Present } \\
(\mathrm{n}=159)\end{array}$} & \multirow{2}{*}{$\begin{array}{c}p- \\
\text { value }\end{array}$} \\
\hline & No. & $\%$ & No. & $\%$ & \\
\hline \multicolumn{6}{|c|}{ Age groups (in years): } \\
\hline$<15$ & 17 & 50.0 & 17 & 50.0 & 0.417 \\
\hline $15-18$ & 201 & 60.9 & 129 & 39.1 & \\
\hline$>18$ & 23 & 63.9 & 13 & 36.1 & \\
\hline \multicolumn{6}{|c|}{ Cigarette smoking: } \\
\hline Smoker & 42 & 60.0 & 28 & 40.0 & 0.962 \\
\hline Non-smoker & 199 & 60.3 & 131 & 39.7 & \\
\hline \multicolumn{6}{|l|}{ Diabetes mellitus: } \\
\hline Yes & 2 & 16.7 & 10 & 83.3 & 0.002 \\
\hline No & 239 & 61.6 & 149 & 38.4 & \\
\hline \multicolumn{6}{|l|}{ Hypertension: } \\
\hline Yes & 6 & 60.0 & 4 & 40.0 & 0.987 \\
\hline No & 235 & 60.3 & 155 & 39.7 & \\
\hline \multicolumn{6}{|c|}{ Family history of IBS: } \\
\hline Yes & 56 & 43.8 & 72 & 56.3 & $<0.001$ \\
\hline No & 185 & 68.0 & 87 & 32.0 & \\
\hline
\end{tabular}

\section{Discussion}

IBS is a common and troublesome health problem. It should not be underestimated since it carries a significant negative impact on the quality of life and social functioning, like decreased concentration, energy, vitality, and self-confidence, with an increase in absence rates from schools and work [10].

This study aimed to assess prevalence, types, and risk factors of IBS among male secondary school students in Najran City, Saudi Arabia.

The present study showed that more than onethird of male secondary school students (39.8\%) expressed symptoms suggestive of IBS. This finding seems to represent a relatively high prevalence of IBS compared with results reported by other studies.

Several community-based studies indicated lower prevalence rates for IBS than those found in the present study, ranging between $10 \%$ and 25\% [11-13] . Epidemiologic studies suggest that irritable bowel syndrome is a common disorder among adults that deserved more attention. In Western countries, the prevalence of IBS in adults ranges from $8 \%$ to $23 \%$. In Africa, the rate was about $10 \%$. In Asia, it was about 5\% [14].

Lovell and Ford [15] stated that the international prevalence of IBS showed a wide range of varia- bility within each geographical region. In North America, its prevalence approaches $21 \%$, while in South Asia, it is $7 \%$.

In Saudi Arabia, high prevalence rates of IBS were reported by Ibrahim [16] among university students (31.8\%), and by Al-Ghamdi et al. [17] $(21 \%)$.

Canavan et al. [18] noted that prevalence estimates for IBS vary considerably both within and between countries. Some of these variationscan be explained through differences in study methodology and sampling and the use of different diagnostic criteria to define IBS, rather than a biological marker, which may also account for some of the variation.

The high prevalence of IBS among secondary school male students in the present study probably reflects the stressful nature of their studies. Saravanan and Wilks [19] noted that it is important to consider the stressors that students experience due to frustration, pressure, and conflict and their reactions to stressors.

Among students who had symptoms of IBS in this study, alternating diarrhea and constipation (i.e., IBS-M) was the most common type affecting more than one-fourth of students, followed by those with diarrhea (i.e., IBS-D), (7.3\%), then, those with constipation (i.e., IBS-C), (6.5\%).

This finding is in agreement with those reported by several researchers. Abdulmajeed et al. [20], in Egypt, found that most IBS sufferers had alternating symptoms of constipation and diarrhea (IBS-M). Similarly, Hungin et al. [21], in the USA, reported most IBS sufferers (74\%) had alternating symptoms of constipation and diarrhea.

The present study revealed that some variables were significantly associated with a higher prevalence of IBS among male secondary school students, i.e., positive family history of IBS and diabetes mellitus.

The significant association between positive family history and high prevalence of IBS was emphasized by Levy et al. [22], who stated that having a mother with IBS and having a father with IBS are significant independent predictors of IBS and they concluded that heredity contributes to the development of IBS. Saito et al. [23] noted that IBS aggregates strongly in families. There is evidence to support either a possible genetic etiology or a shared household environmental exposure as an underlying cause of IBS. 
Several studies reported a higher prevalence of type 1 diabetes among patients with irritable bowel compared with the general population [24-25]. Moreover, Jurjus et al. [26] suggested that irritable bowel disease and type 2 diabetes is also higher among IBS patients.

The association between diabetes and irritable bowelwas explained by several authors. van Raalte et al. [27] noted that insulin resistance and hyperglycemia among patients with irritable bowel may be attributed to steroid use, which induce elevated serum glucose levels via upregulation of hepatic gluconeogenesis, inhibition of glucose uptake in adipose tissue, and impairment of insulin action. Moreover, Spalinger et al. [28] stated that, in type 1 diabetes, the PTPN2 mutation playsan important role in apoptosis of pancreatic 0 -cells and modulates intestinal epithelial barrierfunction.

\section{Conclusions:}

Prevalence of IBS among Saudi Male Secondary School Students in Najran City is high, with IBS$\mathrm{M}$ being the most common type of IBS, followed by IBS-D. Positive family history of IBS and diabetes mellitus are risk factorsfor IBS. It is recommended to provide health education to secondary school students on how to manage symptoms of IBS, to provide health care services for students to mitigate symptoms of IBS, and to advise smokers, especially those who suffer from symptoms of IBS, to quit smoking. Further studies are needed to identify prevalence and risk factors among female students.

\section{References}

1- QURESHI R.S., ABDELAAL A.M., JANJUA Z.A., ALASMARI H.A., OBAD A.S., ALAMODI A., et al.: Irritable Bowel Syndrome: A Global Challenge Among Medical Students. Cureus, 8 (8): e721. DOI: 10.7759/ cureus.721.

2- AGARWAL N. and SPIEGEL B.M.: The effect of irritable bowel syndrome on health-related quality of life and health care expenditures. Gastroenterol. Clin. North Am., 40: 11-9. DOI: 10.1016/j.gtc.2010.12.013, 2011.

3- DROSSMAN D.A., MORRIS C.B., HU Y., TONER B.B., DIAMANT N., LESERMAN J., SHETZLINE M., DALTON C. and BANGDIWALA S.I.: A prospective assessment of bowel habit in irritable bowel syndrome in women: Defining an alternator. Gastroenterology, 128: 580-589. DOI: 10.1053/j.gastro.2004.12.006, 2005 .

4- KHAN S. and CHANG L.: Diagnosis and management of IBS. Nat. Rev. Gastroenterol. Hepatol., 7: 565-81. DOI: 10.1038/nrgastro.2010.137, 2010.

5- SPILLER R., AZIZ Q., CREED F., EMMANUEL A., HOUGHTON L., HUNGIN P., et al.: Guidelines on the irritable bowel syndrome: Mechanisms and practical management. Gut, 56: 1770-98. DOI: 10.1136/gut.2007. 119446, 2007.

6- MALAGELADA J.R.: A symptom-based approach to making a positive diagnosis of irritable bowel syndrome with constipation. Int. J. Clin. Pract, 60: 57-63. doi: 10.1111/j.1368-5031.2005.00744.x, 2006.

7- DYRBYE L., THOMAS M., EACKER A., HARPER W., MASSIE F., POWER D., HUSCHKA M. and NOVOTNY P.: Race, ethnicity, and medical student well-being in the United States. Arch. Intern. Med., 167: 2103-2109. DOI: 10.1001/archinte.167.19.2103, 2007.

8- ALHAZMI A.H.: Irritable bowel syndrome in secondary school male students in Al-Jouf Province, North of Saudi Arabia. J. Pak. Med. Assoc., 61 (11): 1111-1115, 2011.

9- LACY B.E. and PATEL N.K.: Rome Criteria and a Diagnostic Approach to Irritable Bowel Syndrome. J. Clin. Med., 6 (11): 99. DOI: 10.3390/jcm6110099, 2017.

10- SON Y.J., JUN E.Y. and PARK J.H.: Prevalence and risk factors of irritable bowel in Korean adolescent girls: A school-based study. Int. J. Nurs. Stud., 46 (1): 76-84. DOI: 10.1016/j.ijnurstu.2008.07.006, 2009.

11-OKEKE EN, LADEP N.G., ADAH S., BUPWATDA P.W., AGABA E.I. and MALU A.O.: Prevalence of irritable bowel syndrome: A community survey in an African population. Ann. Afr. Med., 8 (3): 177-180. DOI: 10.4103/ 1596-3519.57241, 2009.

12- OLAFSDOTTIR L.B., GUDJONSSON H., JONSDOTTIR H.H., BJORNSSON E. and THJODLEIFSSON B.: Natural history of functional gastrointestinal disorders: Comparison of two longitudinal population-based studies. Dig. Liver Dis., 44 (3): 211-217. DOI: 10.1016/j.dld.2011.10.009, 2012.

13- GOODWIN L., WHITE P.D., HOTOPF M., STANSFELD S.A. and CLARK C.: Life course study of the etiology of self-reported irritable bowel syndrome in the 1958 British birth cohort. Psychosom Med., 75 (2): 202-210. DOI: 10.1097/PSY.0b013e31827c351b, 2013.

14-DONG L., DINGGUO L., XIAOXING X. and HANMING L.: An Epidemiologic Study of Irritable Bowel Syndrome in Adolescents and Children in China: A School-Based Study. Pediatrics, 116: e393. DOI: 10.1542/peds.20042764, 2005.

15- LOVELL R.M. and FORD A.C.: Global prevalence of and risk factors for irritable bowel syndrome: A metaanalysis. Clinical Gastroenterology and Hepatology, 10: 712-721. DOI: 10.1016/j.cgh.2012.02.029, 2012.

16- IBRAHIM N.K.: A systematic review of the prevalence and risk factors of irritable bowel syndrome among medical students. Turk J. Gastroenterol., 27: 10-6. DOI: 10.5152/ tjg.2015.150333, 2016.

17- AL-GHAMDI S., ALOSAMEY F., ALHAMDAN A., et al.: A study of impact and prevalence of irritable bowel syndrome among medical students. International Journal of Medicine and Medical Sciences, 7 (9): 139-147. DOI: 10.5897/IJMMS2015.1188, 2015.

18- CANAVAN C., WEST J. and CARD T.: The epidemiology of irritable bowel syndrome. Clinical Epidemiology, 6: 71-80. doi: 10.2147/CLEP.S40245, 2014.

19- SARAVANAN C. and WILKS R.: Medical Students' Experience of and Reaction to Stress: The Role of De- 
pression and Anxiety. Scientific World Journal, 2014: 737382. doi: 10.1155/2014/737382, 2014.

20- ABDULMAJEED A., RABAB M.A., SLIEM H.A. and HEBATALLAH N.: Pattern of irritable bowel syndrome and its impact on quality of life in primary healthcare center attendees, Suez Governorate, Egypt. Pan African Medical Journal, 9: 6. doi: 10.4314/pamj.v9i1.71177, 2011.

21- HUNGIN A.P., CHANG L., LOCKE G.R., DENNIS E.H and BARGHOUT V.: Irritable bowel syndrome in the United States: Prevalence, symptom patterns and impact. Aliment Pharmacol. Ther., 21: 1365-75. DOI: 10.1111/ j.1365-2036.2005.02463.x, 2005.

22- LEVY R.L., JONES K.R., WHITEHEAD W.E., FELD S.I., TALLEY N.J. and COREY L.A.: Irritable bowel syndrome in twins: Heredity and social learning both contribute to etiology. Gastroenterology, 121: 799-804. DOI: 10.1053/gast.2001.27995, 2001.

23- SAITO Y.A., PETERSEN G.M., LARSON J.J., ATKINSON E.J., FRIDLEY B.L., de ANDRADE M., et al.: Familial Aggregation of Irritable Bowel Syndrome: A Family Case-Control Study. Am. J. Gastroenterol., 105 (4): 833-841. DOI: 10.1038/ajg.2010.116, 2010.

24- HALLING M.L., KJELDSEN J., KNUDSEN T., NIELSEN
J. and HANSEN L.K.: Patients with inflammatory bowe disease have increased risk of autoimmune and inflammatory diseases. World J. Gastroenterol., 23: 6137-6146. DOI: 10.3748/wjg.v23.i33.6137, 2017.

25- KANG E.A., HAN K., CHUN J., SOH H., PARK S., IM J.P., et al.: Increased Risk of Diabetes in Inflammatory Bowel Disease Patients: A Nationwide Population-Based Study in Korea. J. Clin. Med., 8: 343. DOI: 10.3390/ jcm8030343, 2019 .

26- JURJUS A., EID A., AL KATTAR S., ZEENNY M.N., GERGES-GEAGEA A., HAYDAR H., et al.: Inflammatory bowel disease, colorectal cancer and type 2 diabetes mellitus: The links. BBA Clin., 5: 16-24. DOI: 10.1016/ j.bbacli.2015.11.002, 2016.

27- VAN RAALTE D.H., OUWENS D.M. and DIAMANT M.: Novel insights into glucocorticoid-mediated diabetogenic effects: Towards expansion of therapeutic options? Eur. J. Clin. Investig., 39: 81-93. DOI: 10.1111/j.13652362. 2008.02067.x, 2009.

28- SPALINGER M.R., KASPER S., CHASSARD C., RASELLI T., FREY-WAGNER I., GOTTIER C., et al.: PTPN2 controls differentiation of CD4(+) T cells and limits intestinal inflammation and intestinal dysbiosis Mucosal Immunol., 8: 918-929. DOI: 10.1038/mi.2014. 122,2015

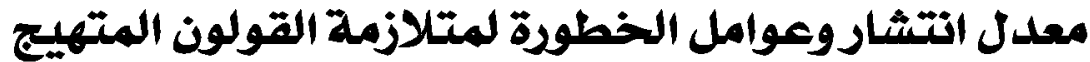

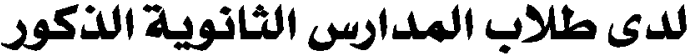 بمدينة نجران، المملكة العربية الفية السعودية الفورية}

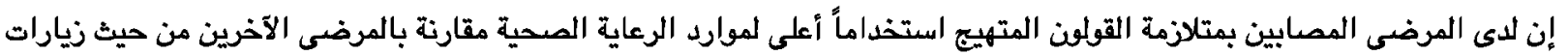

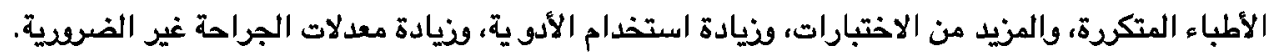

استهدفت هذه الدراسة: تقييم انتشار وأنواع وعوامل الخطر لمتلازمة القولون المتهيج بين طلاب الددارس الثانوية الذكود بمدينة نجران،

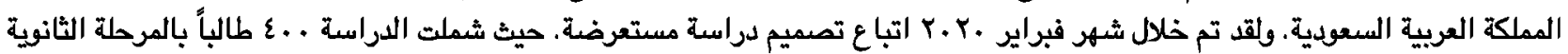

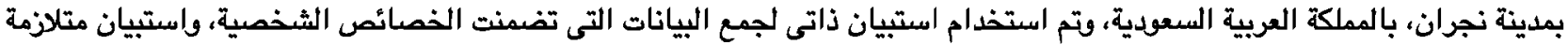

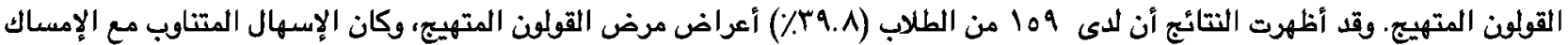
(IBS-M)

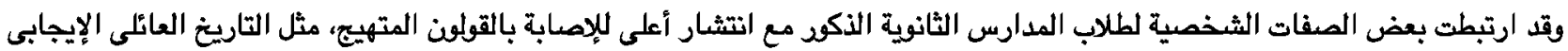

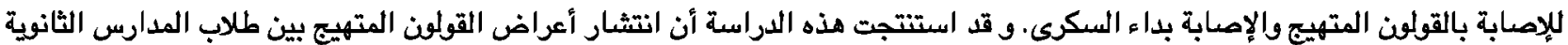

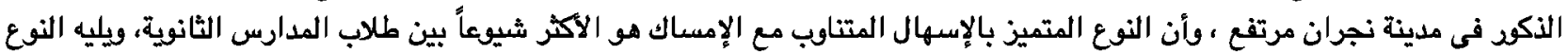

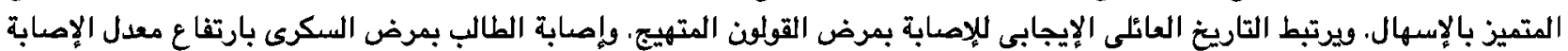

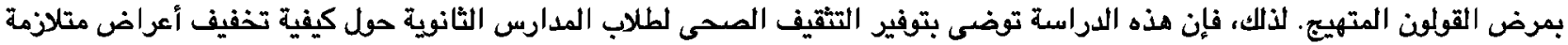
القولون المتهيج وعلاجها. 